\title{
Formation of Various Pyramidal Structures on Monocrystalline Silicon Surface and Their Influence on the Solar Cells
}

\author{
Yangang Han, ${ }^{1,2}$ Xuegong Yu, ${ }^{1}$ Dong Wang, ${ }^{1}$ and Deren Yang ${ }^{1}$ \\ ${ }^{1}$ State Key Lab of Silicon Materials, Zhejiang University, Hangzhou 310027, China \\ ${ }^{2}$ Zhejiang Institute of Quality Inspection Science, Hangzhou 310013, China \\ Correspondence should be addressed to Xuegong Yu; yuxuegong@zju.edu.cn
}

Received 22 June 2013; Accepted 13 July 2013

Academic Editor: Jiamin Wu

Copyright (C) 2013 Yangang Han et al. This is an open access article distributed under the Creative Commons Attribution License, which permits unrestricted use, distribution, and reproduction in any medium, provided the original work is properly cited.

\begin{abstract}
Texturization is a useful method to enhance the optical absorption of monocrystalline silicon wafers by light-trapping effect in solar cell processing. In present study, a series of textured wafers with various pyramid sizes ranging from $200 \mathrm{~nm}$ to $10 \mu \mathrm{m}$ were fabricated by modified wet-chemical method and characterized. The results show that there is little difference in the reflectance with the pyramid sizes from 1 to $10 \mu \mathrm{m}$, which is consistent with the ray-tracing simulation results. However, the light-trapping function of the $200 \mathrm{~nm}$ sample below the geometrical optics limit is much weaker. The solar cells fabricated from the $1 \mu \mathrm{m}$ samples own the highest power conversion efficiency of $18.17 \%$ due to a better coverage of metal finger lines than the larger ones, and the $200 \mathrm{~nm}$ samples have the lowest efficiency of $10.53 \%$.
\end{abstract}

\section{Introduction}

The demand for utilizing solar energy has significantly increased in the past few years. Despite relevant photovoltaic technologies being available for more than half a century, the power conversion efficiencies remain relatively low, which lie in the $10-18 \%$ range for most of the manufactured output $[1,2]$. Up to now, anisotropic etching on (100)-oriented monocrystalline silicon wafers to form square-based pyramid units randomly distributed over the surface using alkaline solution has been proved to be an important and effective way to reduce the reflectivity from the front surface of silicon solar cells and improve the efficiency $[3,4]$. As a result, the reflectivity of the textured silicon wafers is about $20 \%$ lower than that of the flat ones. The alkaline solution containing sodium hydroxide $(\mathrm{NaOH})$ and isopropyl alcohol (IPA) is widely used in industrial batch process [5]. Normally the average pyramid size is varying from $2 \mu \mathrm{m}$ to $8 \mu \mathrm{m}$, and the corresponding reflectivity is in the range of $14-15 \%$ [6-9]. To maintain stability during the texturing process, IPA must be added to the solution frequently to keep it in the same concentration because of the evaporation of IPA. Recent researches have been concentrated on investigating new texturing methods and alternative solutions. Nishimoto and Vallejo textured silicon wafers by using sodium carbonate solution without adding IPA [10, 11], and the resultant pyramid size was in the range of $4-7 \mu \mathrm{m}$. Chu textured silicon wafers using a metal grid with suitable openings on them to confine the hydrogen bubbles, and the structure with the pyramid size of 6 to $9 \mu \mathrm{m}$ was obtained [12,13]. However, it was very difficult to fabricate large-area metal grids and control the distance between the grid and silicon wafers. Chen fabricated more uniform pyramids in the size of $1 \mu \mathrm{m}$ using reactive ion etching (RIE) [14] and achieved a lower reflectivity. Mavrokefalos synthesized inverted nanopyramid applicable for thin silicon films using standard scalable microfabrication techniques based on interference lithography and wet silicon etching [15]. A broadband enhancement in absorption was achieved using that two-step method with prepatterned holes. Ordered pyramidal structures can also be fabricated by colloidal lithography with packed polystyrene spheres [16] or silica colloidal crystals as masks [17]. However, the process was complicated and needed expensive instruments.

As we mentioned above, textured silicon wafers with different pyramid size can only be synthesized using separate method. And the influence of texture feature size on the optical performance and conversion efficiency of silicon solar cells is still unknown. In present study, textured 


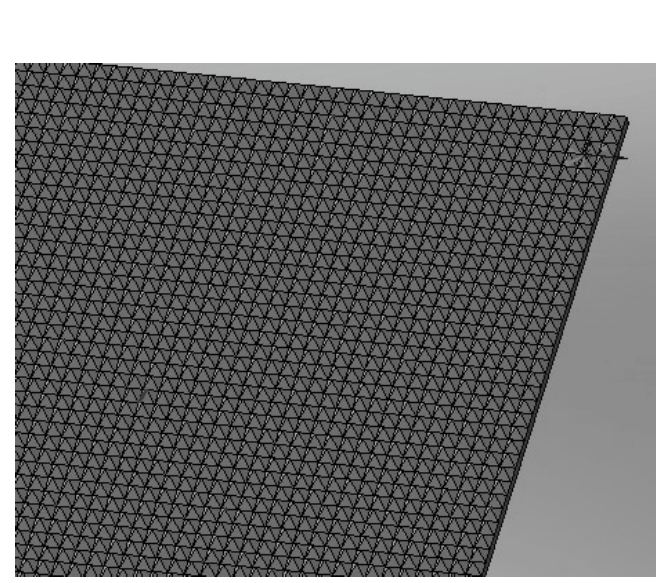

(a)
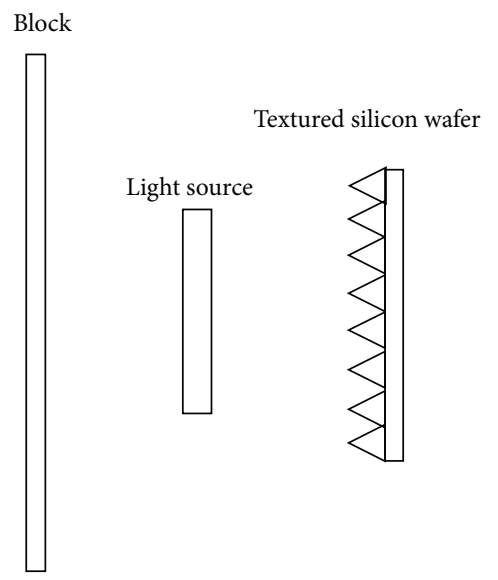

(b)

FIGURE 1: (a) Model of textured silicon wafer used in our simulations and (b) schematic diagram of the simulation system. The block behind the light source is used to collect the reflective rays.

monocrystalline silicon wafers with various pyramid sizes (from $200 \mathrm{~nm}$ to $10 \mu \mathrm{m}$ ) were fabricated in the same way using different additives. The light-trapping function was evaluated by measuring the reflectivity of different textured wafers. Also the ray-tracing simulations of light-trapping in textured wafers based on geometrical optics were conducted. Finally, solar cells made from different textured wafers were fabricated, and a power conversion efficiency of $18.17 \%$ was achieved under optimized conditions.

\section{Experimental Section}

2.1. Texturing Process. The p-type, (100)-oriented monocrystalline silicon wafers with a resistivity of $0.5-3 \Omega \cdot \mathrm{cm}$ and a thickness of $200 \mu \mathrm{m}$ were used in our experiments. Before any etching process, the wafers were cleaned by Radio Corporation America (RCA) method to remove the metal ions and rinsed in deionized water $(18 \mathrm{M} \Omega)$. Then, the saw damage removal (SDR) was carried out by dipping the wafers into an aqueous solution containing $20 \mathrm{wt} \% \mathrm{NaOH}$ at $80^{\circ} \mathrm{C}$ for $10 \mathrm{~min}$ and then rinsed thoroughly. The thickness of the wafers decreased to about $170 \mu \mathrm{m}$ after that procedure. After the pretreatments mentioned above, the wafers were dipped in modified texturing solutions containing $\mathrm{NaOH}$ (1.5 $\mathrm{wt} \%)$, IPA (4 vol\%), and one kind of additives ( $0.1 \mathrm{wt} \%$ of $\mathrm{Na}_{2} \mathrm{SiO}_{3}, 0.06$ vol\% of PEG, and $0.01 \mathrm{vol} \%$ of NPE) for $25 \mathrm{~min}$. The reaction vessel was sealed during the whole process in order to prevent the chemicals from evaporation, and no agitation was needed. The inside temperature was kept at $80^{\circ} \mathrm{C}$. After etching, the wafers were rinsed again in the flowing deionized water and dried with blowing $\mathrm{N}_{2}$. The surface morphology of textured wafers was investigated by a HITACHI S-4800 Scanning Electron Microscope (SEM), and the optical property was measured with a HITACHI U-4100 Spectrophotometer.

2.2. Software Simulations. The process of simulations obeys the law of geometrical optics. When an incident ray arrives at the surface of the silicon wafer, it is divided into the refraction ray which is absorbed by the silicon and the reflection ray which is reflected back to the air. The intensities of those two kinds of rays depend on the refractive index of silicon [18]. The simulations were performed on TracePro 6.0 developed by Lambda Research Corporation based on geometrical optics. An area of $480 \mu \mathrm{m} \times 480 \mu \mathrm{m}$ and a thickness of $170 \mu \mathrm{m}$ were used in our simulations. The light source area was $240 \mu \mathrm{m} \times 240 \mu \mathrm{m}$ and the wavelength of the light source was between 300 and $1100 \mathrm{~nm}$. A ray of 90000 numbers was randomly generated with a total power of $1 \mathrm{~W}$. The optical property of the reference model could be obtained by testing the reflectivity of a polished monocrystalline silicon wafer. The front surface of the wafer was textured to pyramidal structure with the top angle of $70.6^{\circ}$, while the back surface was polished as shown in Figure 1. The intensity of final reflection ray is much lower than that of initial incident ray because of the repetitious reflection and absorption by the silicon.

2.3. Fabrication of Solar Cell Devices. The solar cells were made from different types of textured wafers and fabricated via a conventional solar cell process, which includes phosphorous doping on the textured front side, thermal diffusion of phosphorus, formation of a silicon nitride antireflection coating on the textured front side, metallization, and firing. The size of the solar cells was $125 \mathrm{~mm} \times 125 \mathrm{~mm}$. After the device fabrication process, the I-V characteristics under illumination were measured using an Oriel I-V Test Station under Air Mass 1.5 Global (AM 1.5G) illumination conditions at room temperature. All measurements were carried out using 16 samples, and the mean values were used as the results.

\section{Results and Discussion}

3.1. Morphology of Textured Wafers. Figure 2 shows typical SEM images of the wafers etched in $\mathrm{NaOH} / \mathrm{IPA}$ solutions 

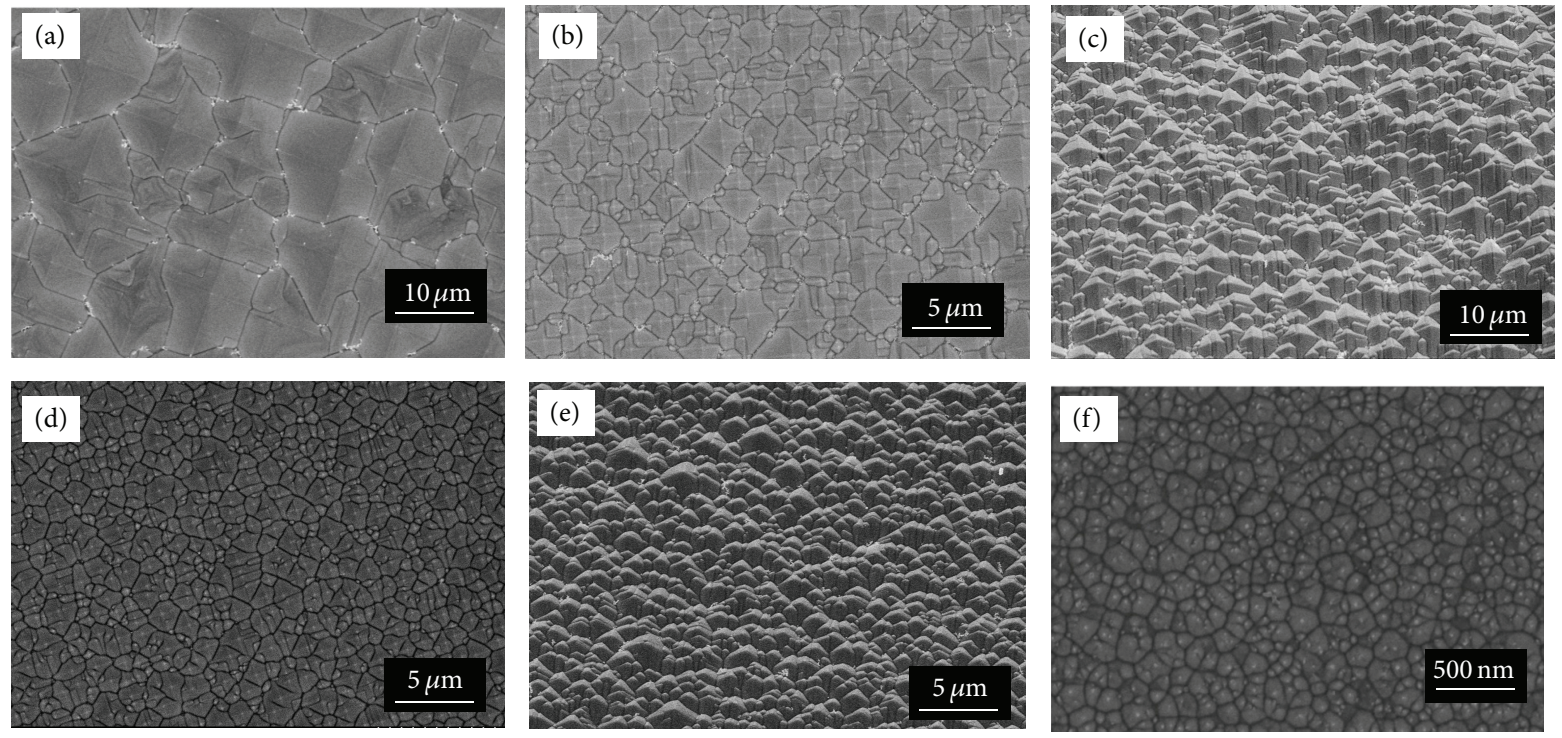

FIgure 2: Typical SEM images of the wafers textured at $80^{\circ} \mathrm{C}$ for $25 \mathrm{~min}$ with different additives: (a) no additive, (b) and (c) $\mathrm{Na}_{2} \mathrm{SiO}_{3}$, (d) and (e) PEG, and (f) NPE.

at $80^{\circ} \mathrm{C}$ for $25 \mathrm{~min}$. Different additives $\left(\mathrm{Na}_{2} \mathrm{SiO}_{3}, \mathrm{PEG}\right.$, and NPE) were used to moderate the reaction speed and reduce the silicon/electrolyte interfacial energy to obtain special pyramid units [5]. Etching without additives was also conducted for comparison. As shown in Figure 2, various sizes of upright pyramids ranging from $10 \mu \mathrm{m}$ to $200 \mathrm{~nm}$ and distributed on the surface of the wafers have been prepared. For the traditional sample etched without additive, typical structure with the pyramid size of about $10 \mu \mathrm{m}$ can be obtained. However, there are many smaller pyramids around larger ones. For the sample etched with $\mathrm{Na}_{2} \mathrm{SiO}_{3}$, the typical pyramid size decreases to about $5 \mu \mathrm{m}$, and the uniformity has been improved. $\mathrm{Na}_{2} \mathrm{SiO}_{3}$ aqueous solution contains large numbers of nonpolar and polar functional parts, which reduces the surface tension of the etching solution and provides sufficient pyramid nucleation points to make the surface arrangement closer. PEG and NPE, which have many hydroxyl groups on the polymer chains, might play the same role as IPA during etching. The etching solutions containing PEG or NPE could be employed to fabricate the pyramid units of about $1 \mu \mathrm{m}$ or $200 \mathrm{~nm}$, respectively.

3.2. Optical Property of Textured Wafers. The reflectivity of textured wafers with different pyramid sizes was plotted in Figure 3. The $1 \mu \mathrm{m}$ sample owns the lowest reflectivity of $11.2 \%$, and there is little difference in the reflectivity especially in the visible region, with the exception of the $200 \mathrm{~nm}$ sample. The degradation of the reflectance with respect to the geometrical optics limit when the pyramid size is below $300 \mathrm{~nm}$ is then related to diffraction effects becoming noticeable, approaching that of a flat surface for smaller sizes [19].

Nearly no dependence of reflectance on the pyramid size could be explained by ray-tracing in the geometrical optics regime when the surface features are much larger than the wavelength. When the pyramid size decreases to

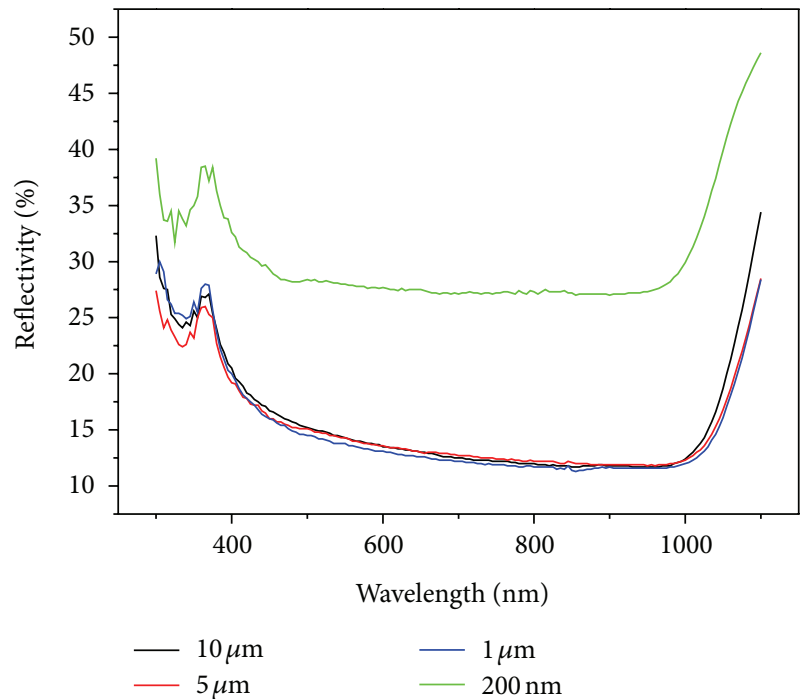

FIGURE 3: The reflectivity of textured wafers with different pyramid sizes.

a value which is lower than the wavelength of the incident light, the law of geometrical optics does not fit for that structure because the light should be seen as a wave. Figure 4 compares the reflectivity of simulation values and chemicaletching wafers with different pyramid sizes $(1-10 \mu \mathrm{m})$. The wavelength of the incident light was 400, 500, 600, and $700 \mathrm{~nm}$, respectively. The top angle was set to $70.6^{\circ}$, which is similar to the chemical-etching structure. As we can see from the picture, the simulated reflectivity is almost the same for different wafers under every incident light and the value is close to the experimental result. The experimental value is slightly higher than the simulated one because the structure used in our simulations is much more uniform and regular [18]. 
TABLE 1: Device parameters of the solar cells based on textured wafers with different pyramid sizes.

\begin{tabular}{lcccr}
\hline Wafer type & $I_{\text {sc }}(\mathrm{A})$ & $V_{\text {oc }}(\mathrm{V})$ & FF & Eff. $(\%)$ \\
\hline $10 \mu \mathrm{m}$ & $5.74\left(0.0108^{\mathrm{a}}\right)$ & $0.62(0.0170)$ & $0.77(0.0117)$ & $17.81(0.1126)$ \\
$5 \mu \mathrm{m}$ & $5.72(0.0108)$ & $0.62(0.0169)$ & $0.76(0.0115)$ & $17.62(0.1114)$ \\
$1 \mu \mathrm{m}$ & $5.76(0.0109)$ & $0.63(0.0166)$ & $0.78(0.0118)$ & $18.17(0.1148)$ \\
$200 \mathrm{~nm}$ & $4.61(0.0087)$ & $0.62(0.0129)$ & $0.56(0.0085)$ & $10.53(0.0665)$ \\
\hline
\end{tabular}

${ }^{\mathrm{a}}$ Standard deviation.

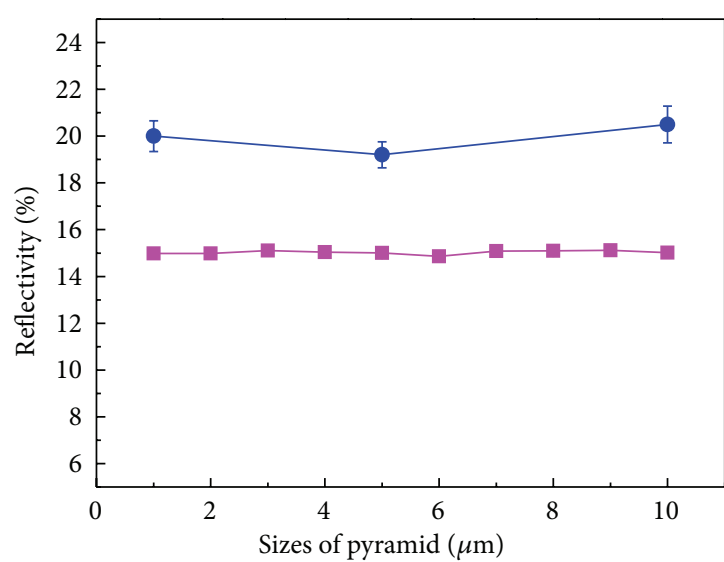

(a)

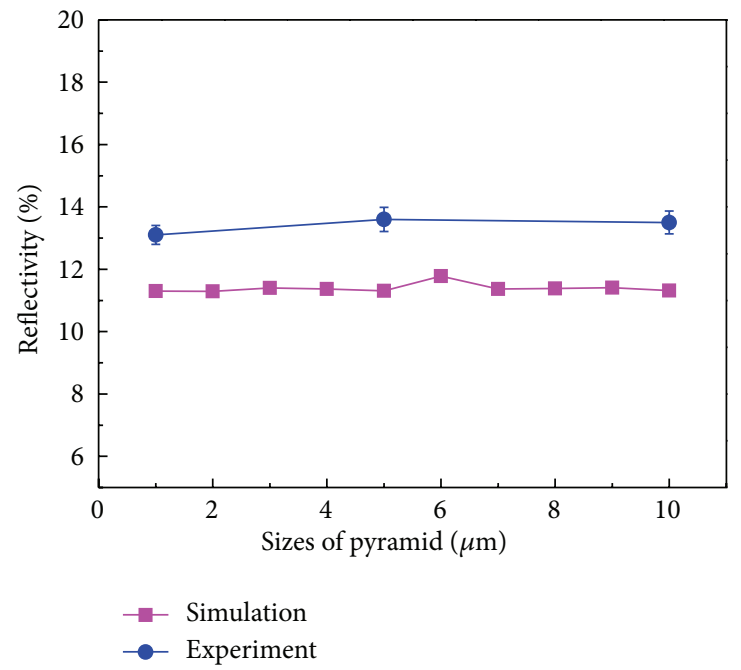

(c)

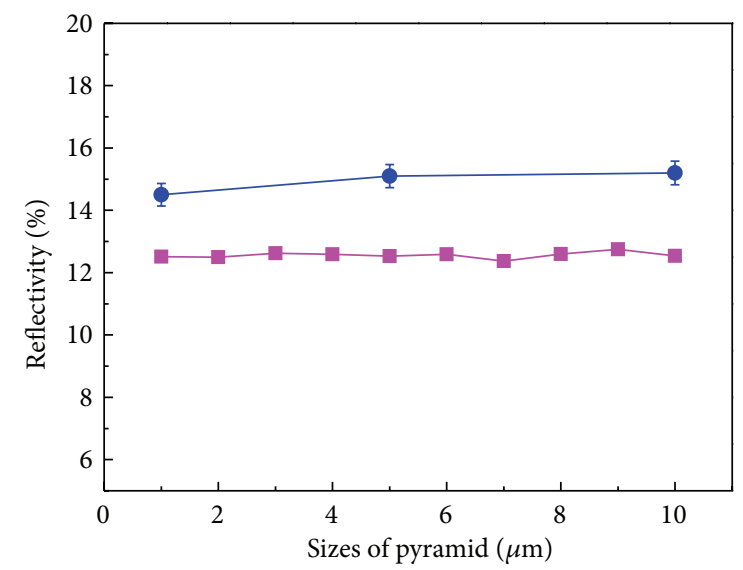

(b)

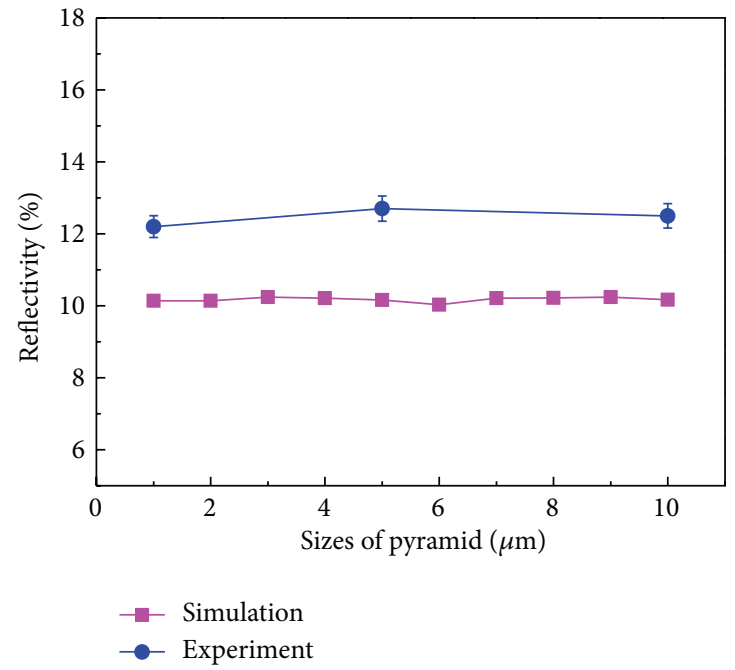

(d)

FIGURE 4: Influence of the pyramid size on the reflectivity of textured wafers. The wavelength of the incident light is (a) $400 \mathrm{~nm}$, (b) $500 \mathrm{~nm}$, (c) $600 \mathrm{~nm}$, and (d) $700 \mathrm{~nm}$. Each point and error bar (in blue) represents the mean value and standard deviation of five replicate experiments, respectively.

3.3. Performance of Solar Cell Devices. The solar cells made from different types of textured wafers were fabricated via a conventional solar cell process, and the device parameters are summarized in Table 1 . The textured morphology does not affect the open circuit voltage $\left(V_{\mathrm{oc}}\right)$ for all the devices. However, the cell made from the $200 \mathrm{~nm}$ wafer has a short circuit current $\left(I_{\mathrm{sc}}\right)$ of $4.61 \mathrm{~A}$ and an overall conversion efficiency (Eff.) of $10.53 \%$, which are both much lower than those of the other three devices because of high reflection loss and less formed electron-hole pairs [20]. The $10 \mu \mathrm{m}$ and $5 \mu \mathrm{m}$ devices have the similar cell performance. Although different textured samples except the $200 \mathrm{~nm}$ one show similar reflectance values, the device fabricated from the $1 \mu \mathrm{m}$ wafer exhibits a highest conversion efficiency of $18.17 \%$ for the possible reason that the printing metal finger lines could have a better coverage on smaller pyramidal structure than larger one [21].

\section{Conclusions}

Different pyramidal surface structures were realized on etched monocrystalline silicon wafers with modified alkaline 
solutions, and the typical pyramid sizes were ranging from $200 \mathrm{~nm}$ to $10 \mu \mathrm{m}$. Little dependence of reflectance on the size of the textured pyramids is observed except the $200 \mathrm{~nm}$ wafer, which is approved by the effective and reliable ray-tracing simulation technology. The solar cells fabricated using the $1 \mu \mathrm{m}$ wafers own the highest conversion efficiency of $18.17 \%$ among all the four kinds of devices due to the better coverage of metal finger lines on smaller pyramidal structures.

\section{References}

[1] A. Polman and H. A. Atwater, "Photonic design principles for ultrahigh-efficiency photovoltaics," Nature Materials, vol. 11, no. 3, pp. 174-177, 2012.

[2] X. Y. Huang, S. Y. Han, W. Huang, and X. G. Liu, "Enhancing solar cell efficiency: the search for luminescent materials as spectral converters," Chemical Society Reviews, vol. 42, no. 1, pp. 173-201, 2013.

[3] M. A. Green, "Crystalline and thin-film silicon solar cells: state of the art and future potential," Solar Energy, vol. 74, no. 3, pp. 181-192, 2003.

[4] L. Forbes, "Texturing, reflectivity, diffuse scattering and light trapping in silicon solar cells," Solar Energy, vol. 86, no. 1, pp. 319-325, 2012.

[5] E. Vazsonyi, K. De Clercq, R. Einhaus et al., "Improved anisotropic etching process for industrial texturing of silicon solar cells," Solar Energy Materials and Solar Cells, vol. 57, no. 2, pp. 179-188, 1999.

[6] R. Barrio, N. González, J. Cárabe, and J. J. Gandía, "Optimisation of $\mathrm{NaOH}$ texturisation process of silicon wafers for heterojunction solar-cells applications," Solar Energy, vol. 86, no. 3, pp. 845-854, 2012.

[7] E. Manea, E. Budianu, M. Purica et al., "Optimization of front surface texturing processes for high-efficiency silicon solar cells," Solar Energy Materials and Solar Cells, vol. 87, no. 1-4, pp. 423-431, 2005.

[8] Z. Q. Xi, D. R. Yang, W. Dan, C. Jun, X. H. Li, and D. L. Que, "Investigation of texturization for monocrystalline silicon solar cells with different kinds of alkaline," Renewable Energy, vol. 29, no. 13, pp. 2101-2107, 2004.

[9] Z. Q. Xi, D. R. Yang, and D. L. Que, “Texturization of monocrystalline silicon with tribasic sodium phosphate," Solar Energy Materials and Solar Cells, vol. 77, no. 3, pp. 255-263, 2003.

[10] B. Vallejo, M. González-Mañas, J. Martínez-López, and M. A. Caballero, "On the texturization of monocrystalline silicon with sodium carbonate solutions," Solar Energy, vol. 81, no. 5, pp. 565-569, 2007.

[11] Y. Nishimoto and K. Namba, "Investigation of texturization for crystalline silicon solar cells with sodium carbonate solutions," Solar Energy Materials and Solar Cells, vol. 61, no. 4, pp. 393402, 2000.

[12] A. K. Chu, J. S. Wang, Z. Y. Tsai, and C. K. Lee, "A simple and cost-effective approach for fabricating pyramids on crystalline silicon wafers," Solar Energy Materials and Solar Cells, vol. 93, no. 8, pp. 1276-1280, 2009.

[13] H. H. Li, W. F. Liu, A. Liu, F. Qiao, Z. Hu, and Y. Liu, "Metal grids-based texturization of monocrystalline silicon wafers for solar cells," Solar Energy Materials and Solar Cells, vol. 94, no. 6, pp. 942-945, 2010.

[14] H. L. Chen, W. Fan, C. C. Cheng, C. H. Lin, and K. T. Huang, "Fabrication of texturing antireflection structures in solar cells by using the defocusing exposure in optical lithography," Journal of the Electrochemical Society, vol. 153, no. 9, pp. G802-G806, 2006.

[15] A. Mavrokefalos, S. E. Han, S. Yerci, M. S. Branham, and G. Chen, "Efficient light trapping in inverted nanopyramid thin crystalline silicon membranes for solar cell applications," Nano Letters, vol. 12, no. 6, pp. 2792-2796, 2012.

[16] H. L. Chen, S. Y. Chuang, C. H. Lin, and Y. H. Lin, "Using colloidal lithography to fabricate and optimize sub-wavelength pyramidal and honeycomb structures in solar cells," Optics Express, vol. 15, no. 22, pp. 14793-14803, 2007.

[17] X. M. Zhang, J. H. Zhang, Z. Y. Ren et al., "Morphology and wettability control of silicon cone arrays using colloidal lithography," Langmuir, vol. 25, no. 13, pp. 7375-7382, 2009.

[18] X.-S. Hua, Y.-J. Zhang, and H.-W. Wang, "The effect of texture unit shape on silicon surface on the absorption properties," Solar Energy Materials and Solar Cells, vol. 94, no. 2, pp. 258$262,2010$.

[19] F. Llopis and I. Tobías, "Influence of texture feature size on the optical performance of silicon solar cells," Progress in Photovoltaics, vol. 13, no. 1, pp. 27-36, 2005.

[20] H. Sai, Y. Kanamori, K. Arafune, Y. Ohshita, and M. Yamaguchi, "Light trapping effect of submicron surface textures in crystalline Si solar cells," Progress in Photovoltaics, vol. 15, no. 5, pp. 415-423, 2007.

[21] U. Gangopadhyay, K. H. Kim, S. K. Dhungel et al., "A novel low cost texturization method for large area commercial monocrystalline silicon solar cells," Solar Energy Materials and Solar Cells, vol. 90, no. 20, pp. 3557-3567, 2006. 

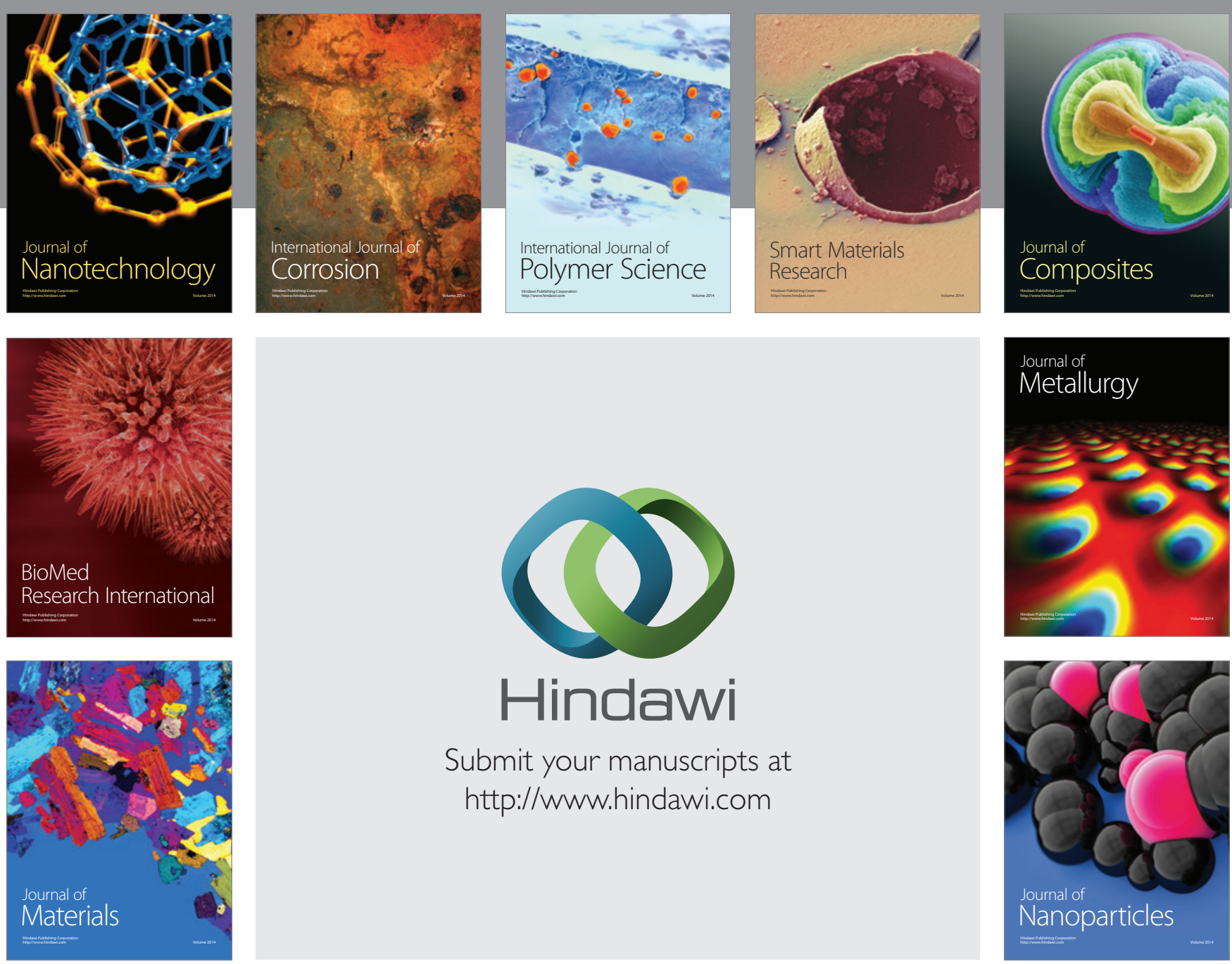

Submit your manuscripts at http://www.hindawi.com
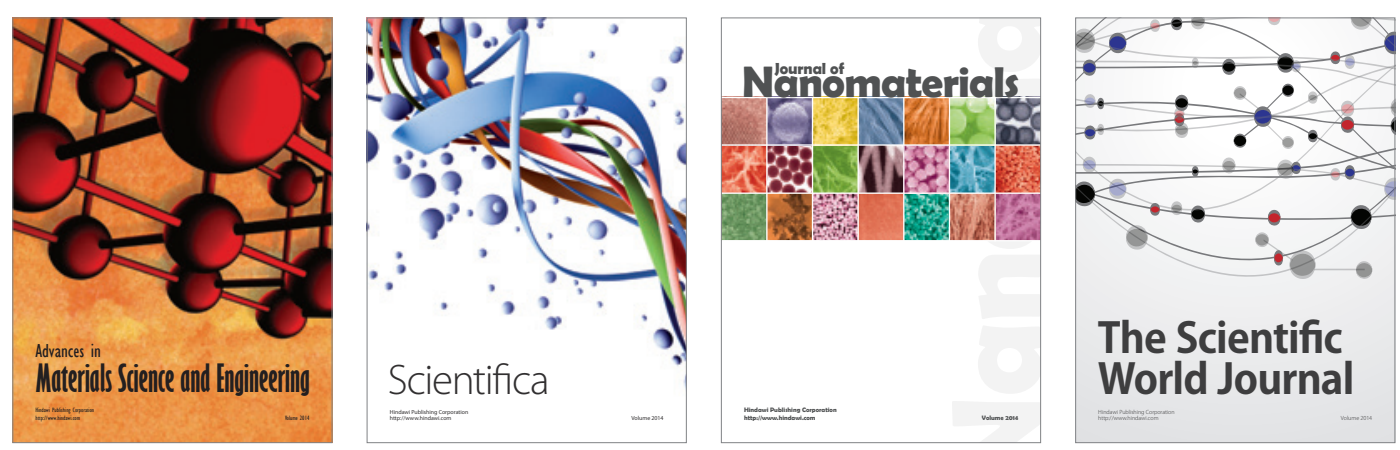

\section{The Scientific World Journal}
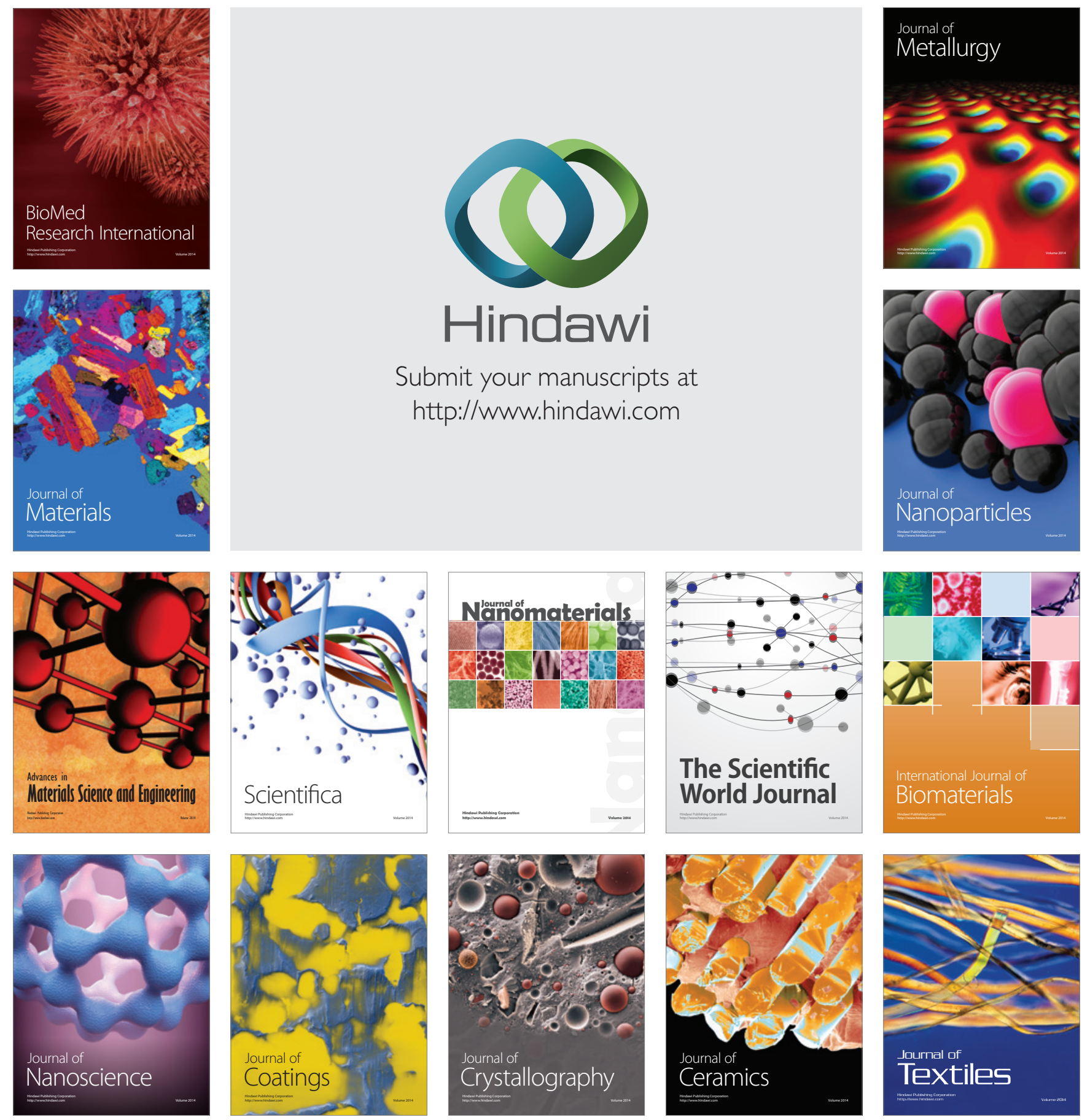